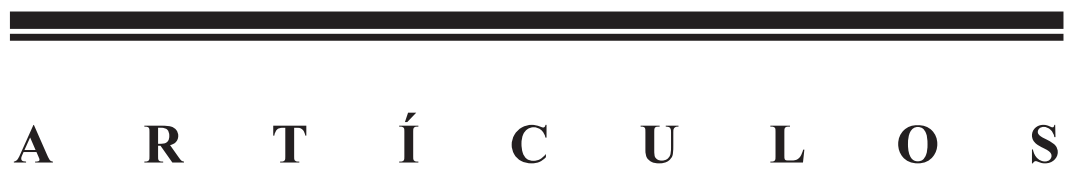




\section{JUSTICIA Y BIENESTAR. DESDE UNA PERSPECTIVA DE DERECHO COMPARADO}

Horacio Spector*

Universidad Torcuato Di Tella, Buenos Aires

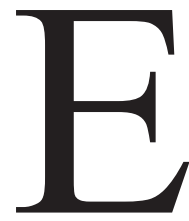

n la Edad Media, la doctrina jurídica iusprivatista comenzó a desarrollar una estructura teórica capaz de explicar y sistematizar el conjunto de las normas de Derecho Romano. Este proceso culminó durante los siglos XVIII y XIX con la redacción de los códigos civiles europeos y latinoamericanos. Luego de que la codificación fue puesta en práctica, y completada con la sanción del Código Civil alemán (BGB), la ciencia jurídica comenzó a declinar en vitalidad intelectual. Aunque los juristas todavía trabajan en la sistematización de las normas codificadas y, en particular, de las decisiones judiciales que buscan ajustar el código a las nuevas circunstancias económicas, sociales y tecnológicas, esta actividad carece de la sofisticación teórica que marcó los estudios civilistas de la pre-codificación. En gran medida, esto se debe al hecho de que los juristas civilistas completaron, a todos los efectos prácticos, el proceso de redescubrimiento y sistematización del Derecho Romano que sentó las bases para la codificación.

En las últimas décadas, los juristas norteamericanos han producido una revolución intelectual al aplicar la economía y la filosofía moral al estudio de instituciones jurídicas particulares. Los analistas económicos del derecho y los filósofos del derecho compiten en tratar de ofrecer la explicación más

* Profesor de Derecho, Decano de la Escuela de Derecho y Vicerrector, Universidad Torcuato Di Tella. Esta es una versión revisada de un trabajo presentado al Special Workshop on Law and Economics and Legal Scholarship, 21st IVR World Congress, Lund, Suecia (Agosto 12-18, 2003). Un trabajo relacionado (a publicarse en Louisiana Law Review) fue presentado como la Conferencia Tucker en el Centro de Derecho Paul M. Hebert de la Universidad del Estado de Luisiana el 20 de marzo de 2003. Agradezco los comentarios valiosos hechos por Marcelo Ferrante, Guido Pincione, Fernando Tesón, así como por las audiencias en esos encuentros. La versión original de este trabajo fue publicada en Chicago-Kent Law Review, Vol. 79:2 (2004). La traducción al castellano fue realizada por Martín Hevia (estudiante de posgrado en la Escuela de Derecho de la Universidad de Toronto). 
exitosa de diferentes campos del common law. ${ }^{1}$ Los paradigmas resultantes han enriquecido la investigación jurídica de una forma sin precedentes. En este artículo, trataré de determinar si, y, en caso afirmativo, con qué alcance, esos estudios teóricos pueden ser útiles para explicar el derecho privado que rige en las jurisdicciones de derecho romanista o codificado. Mi propósito es tanto intelectual como práctico. Intelectualmente, me ocupo de la importancia relativa de la justicia y de la eficiencia en el derecho codificado. Prácticamente, estoy interesado en redirigir el foco de la investigación civilista hacia los fundamentos económicos y filosóficos del derecho. Los estudios filosóficos también podrían servir para restaurar la continuidad intelectual entre la filosofía moral y la doctrina civilista, que era evidente antes de la codificación.

\section{La economía y la filosofía moral en la investigación jurídica del Common Law}

La idea de que la doctrina jurídica es una ciencia acompañó el nacimiento de la investigación jurídica estadounidense. Como dice el decano Anthony Kronman, Langdell defendió la interpretación hobbesiana del derecho y de la política como un tipo de geometría cuyos principios fundacionales podrían ser descubiertos por la razón natural. ${ }^{2}$ En oposición a la concepción clásica del common law como un reino de sabiduria práctica y de experiencia, Langdell adhirió a las tesis básicas de los formalistas jurídicos tales como Bentham y Austin, quienes pensaban que el derecho podía reconstruirse como un orden racional. En vez de favorecer una reconstrucción desde afuera, en la forma de códigos civiles, Langdell sostuvo que los profesores de derecho podían reconstruir las decisiones del common law desde adentro para lograr un sistema "geométrico" de principios jurídicos.

A pesar de la concepción langdelliana de la doctrina jurídica del common law como ciencia formal, la investigación jurídica norteamericana normalmente no es llamada ciencia. La razón posiblemente resida en el hecho de que, a diferencia de la doctrina iusprivatista romanista, no alcanzó un grado alto de sistematización abstracta. Solamente en las ultimas décadas, con el surgimiento del análisis económico del derecho, la doctrina jurídica norteamericana está alcanzando un grado alto de teorización y de complejidad analítica. ${ }^{3}$

\footnotetext{
${ }^{1}$ Para un ejemplo reciente de la controversia, defendiendo el punto de vista económico, ver Louis Kaplow \& Steven Shavell, Fairness Versus Welfare (2002).

${ }^{2}$ Anthony T. Kronman, The Lost Lawyer: Failing Ideals of the Legal Profession 170-85 (1993).

${ }^{3}$ Esto llevó al Profesor Ulen a sostener que la investigación jurídica en sí misma se está convirtiendo en una ciencia nueva. Ver Thomas S. Ulen, A Nobel Prize in Legal Science:
} 
Es importante destacar el medio intelectual en el que surgió el análisis económico del derecho. A principios de los sesenta, la filosofía política y moral anglo-americana todavía estaba bajo la influencia del utilitarismo, que había logrado una posición preeminente durante el siglo XIX a través del trabajo de seguidores de Jeremy Bentham tales como James Mill, James Stuart Mill y Henry Sigdwick. Durante el siglo XX, el utilitarismo se volvió dominante en la filosofía moral norteamericana y ejerció su influencia en la metafísica y en la epistemología a través del pragmatismo. Al mismo tiempo, el realismo y el instrumentalismo eran las fuerzas intelectuales principales en la teoría jurídica. Nacido como una reacción contra el formalismo langdelliano, el instrumentalismo volvió a tomar vigor con la revolución jurídica que comenzó con Lochner v. New York. La concepción instrumentalista del derecho preparó el terreno para la irrupción de los economistas en la teoría jurídica.

Los trabajos de Ronald Coase y de Guido Calabresi dieron lugar al surgimiento de un enfoque del derecho completamente nuevo, popularizado en las escuelas de derecho norteamericanas por Richard Posner. El enfoque económico del derecho gira en torno a la noción de eficiencia o bienestar agregado. Básicamente, dicho enfoque sostiene que las normas jurídicas pueden ser entendidas como intentos institucionales de maximizar el bienestar agregado. En la cultura jurídica norteamericana, la idea de que las normas jurídicas son instrumentos para perseguir diversos fines sociales estaba bien atrincherada en el movimiento realista anti-formalista. Lo novedoso del análisis económico del derecho es que provee un modelo analítico unificado para explicar una formación vasta de normas jurídicas que parecen no tener conexión entre sí. La premisa fundamental de este modelo es que los individuos son agentes racionales que eligen sus acciones para maximizar sus utilidades individuales sobre la base de un orden coherente de preferencias transitivas. ${ }^{4}$ El modelo también asume que existe una noción de eficiencia consistente e inteligible que puede servir de base para evaluar las instituciones jurídicas. El paradigma económico del derecho comparte con el utilitarismo la proposición de que el derecho puede asignar benefi-

Theory, Empirical Work, and the Scientific Method in the Study of Law, U. ILL. L. Rev. 875 (2002).

${ }^{4}$ En los ultimos años, los economistas tuvieron que tratar con anomalías conductictas que acosaron a los supuestos de la teoría de la elección racional. Los investigadores del análisis económico del derecho empezaron a debilitar tales supuestos para explicar diferentes normas jurídicas. En este texto, sigo la exposición clásica del análisis económico del derecho como basada en el postulado del Homo oeconomicus debido a que las variaciones recientes del paradigma no alteran las proposiciones que defiendo. Para una reseña de la nueva literatura, ver, e.g., Russell B. Korobkin \& Thomas S. Ulen, Law and Behavioral Science: Removing the Rationality Assumption from Law and Economics, 88 CAL. L. Rev. 1051 (2000). 
cios y cargas entre los diferentes individuos de modo tal que se maximice el bienestar general.

Permítanme ilustrar la explicación económica del derecho con dos ejemplos. Tomo mi primer ejemplo de la responsabilidad extracontractual. En el common law, la noción de culpa descansa en el cuidado que tomaría una persona razonable en las circunstancias especificas. Es notable que haya sido un juez quien propuso una reinterpretación de la culpa en función de los costos y beneficios. En United States v. Carroll Towing Co. ${ }^{5}$, el juez Learned Hand formuló la regla famosa según la cual un agente actúa culposamente cuando la carga del cuidado necesario para evitar un daño es menor a la gravedad del daño multiplicado por la probabilidad de que el daño ocurra. Generalizando la sugerencia de Hand, el análisis económico del derecho define "culpa" como ausencia de cuidado eficiente y sostiene que el objetivo de la responsabilidad extracontractual es maximizar la eficiencia en las esferas sociales en las que las transacciones voluntarias no pueden generar eficiencia debido a los costos de transacción.

Tomaré mi segundo ejemplo del derecho de los contratos. Un cuerpo de bibliografía se ha centrado en la eficiencia relativa de las acciones por incumplimiento contractual tales como la indemnización por daños y perjuicios en función de la expectativa [expectation damages] y la ejecución forzosa de la presentación contractual [specific performance]. De acuerdo con el análisis económico del derecho más convencional, uno de los objetivos del derecho contractual es, y debe ser, asegurar un compromiso óptimo o eficiente con el cumplimiento del contrato. ${ }^{6}$ Esto significa que el derecho debería desalentar el incumplimiento ineficiente. Así, la indemnización en función de la expectativa maximiza el bienestar social porque permite el incumplimiento cuando, y tan sólo cuando, el cumplimiento del contrato es ineficiente. La ejecución forzosa tambien es una accion eficiente, especialmente cuando los costos de renegociación son bajos. ${ }^{7}$ El punto central del análisis económico del derecho contractual es que el precio de un contrato no es una variable independiente del análisis jurídico, sino que más bien depende de las normas jurídicas de fondo. Si el derecho de los contratos impusiera el cumplimiento cualquiera sea el costo para el vendedor (y si la renegociación fuera muy costosa), el precio del contrato sería más alto que si los tribunales ordenaran la indemnización por daños y perjuicios, y el beneficio excedente para ambas partes sería inferior. La teoría del incumplimiento eficiente no ve nada

\footnotetext{
${ }^{5} 159$ F.2d 169, 173 (2d Cir. 1947).

${ }^{6} \mathrm{Ver}$ Robert Cooter \& Thomas Ulen, Law and Economics 189 (3d ed. 2000).

${ }^{7}$ Ver Alan Schwartz, The Case for Specific Performance, 89 YALE L.J. 271 (1979).
} 
de malo en el incumplimiento en sí mismo; sólo se concentra en los costos y en los beneficios resultantes para ambas partes.

Al final de los cincuenta, se hizo evidente que el utilitarismo, al exaltar el bienestar agregado y al diluir las nociones de lo correcto y de lo incorecto, no servía para darle expresión teórica al movimiento de las libertades civiles. Los filósofos políticos y morales comenzaron a reaccionar contra el utilitarismo desarrollando ideas que tomaron prestadas de las teorías contractualistas y de teorías de los derechos naturales que habían prevalecido en la filosofía occidental antes del surgimiento del utilitarismo. A Theory of Justice de John Rawls ${ }^{8}$, que presenta una teoría de la justicia distributiva basada en la filosofía moral kantiana -aunque no en la teoría jurídica de Kant- fue un punto decisivo en este cambio hacia una filosofía basada en el contractualismo y en los derechos.

Algunos años más tarde, la evolución de la teoría jurídica fue paralela a la de la filosofía política. El análisis económico del derecho comenzó a producir explicaciones de una diversidad vasta de campos jurídicos. Tales explicaciones compitieron con los fundamentos tradicionales del common law y, fundamentalmente, con la idea bien arraigada de que la razón de ser del derecho es hacer justicia. En sus formulaciones iniciales, el paradigma económico se inclinaba a ver al derecho como un facilitador del funcionamiento de los mercados libres o como solución a sus anomalías. Los filósofos morales y del derecho no tardaron en enfrentar este paradigma debido a su insensibilidad al papel de la justicia y de la equidad en el derecho. El desafío se facilitó debido al convencimiento de que la explicación económica del common law presentaba anomalías. Luego, en los setenta y en los ochenta, algunos filósofos del derecho norteamericanos lideraron un proceso similar al que había liderado Rawls en la filosofía política. Así como el pensamiento de Rawls estaba motivado por el objetivo de establecer fundamentos kantianos, no agregados, para una constitución política capaz de combinar el libertarianismo civil y el estado de bienestar, la reacción contra el análisis económico del derecho surgió de una hostilidad hacia el utilitarismo y hacia los mercados libres irrestrictos.

En la actualidad, un grupo grande de filósofos del derecho norteamericanos están embarcados en el proyecto de interpretar el common law en función de ideas morales tales como justicia y equidad. Tales autores se inspiran en Kant y otros filósofos del iusnaturalismo racionalista y se oponen a la posición que ve a las instituciones del common law como instrumentos para lograr el bienestar agregado. Las teorías basadas en la noción de justicia que surgieron de este proyecto teórico compiten con el análisis económico

\footnotetext{
${ }^{8}$ John RaWls, A Theory of Justice (1971).
} 
del derecho, del mismo modo en que las teorías basadas en la noción de derechos compiten con el utilitarismo en el campo de la filosofía política. Mientras que los filósofos del derecho en los países del common law están ocupados en un análisis profundo de diversas áreas del derecho, su contraparte en los países de tradición civilista se quejan habitualmente de que los juristas ignoran las contribuciones filosóficas que podrían darle mayor claridad y precisión a las doctrinas jurídicas. Si bien esto es cierto, también es innegable que, más allá de claridad y precisión, la filosofía jurídica positivista no tiene demasiado para ofrecerle al doctrinario. En general, el positivismo se preocupa de las nociones jurídicas más abstractas, tales como "validez" o "sistema jurídico", antes que de cuestiones jurídicas más específicas. Sin duda, el uso apropriado de tales conceptos puede terminar con varias confusiones y errores que afloran en las investigaciones jurídicas. Pero el filósofo del derecho tradicional no puede decir demasiado acerca de, por ejemplo, cuestiones concretas del responsabilidad extracontractual o del derecho de los contratos. Los filósofos del derecho en las jurisdicciones de common law discuten cuestiones específicas y buscan dar explicaciones que rivalizan con las explicaciones defendidas por sus competidores economistas en cuanto a su sofisticación. Ilustraré este enfoque nuevo refieriéndome, nuevamente, a la responsabilidad extracontractual y al derecho de los contratos.

En un ensayo pionero publicado a principios de los setenta, el Profesor George Fletcher descubrió la existencia de dos paradigmas en la responsabilidad extracontractual: el "paradigma de la reciprocidad" y el "paradigma de la razonabilidad". 9 Mientras que este último está dirigido hacia el bienestar de la comunidad, el primero presupone una idea distintiva de equidad: "todos los individuos de la sociedad tienen el derecho a aproximadamente el mismo grado de seguridad con respecto al riesgo". ${ }^{10}$ Según Fletcher, la responsabilidad extracontractual -tanto en la responsabilidad objetiva como en la variante basada en la culpa- expresa el ideal de justicia correctiva al reconocer el derecho de la víctima a ser resarcida por los daños que resultan de riesgos que no son recíprocos. Si bien Fletcher sostiene que ambos paradigmas están presentes en la responsabilidad extracontractual, adjudica mayor importancia al paradigma de la reciprocidad. En efecto, Fletcher sostiene que, puesto que el paradigma del bienestar está comprometido con la maximización de la utilidad social, no logra respetar el valor de la autonomía individual. Jules Coleman, Stephen Perry, Ernest Weinrib y Richard Wright, entre otros, siguieron a Fletcher en la adopción de la interpretación

\footnotetext{
${ }^{9}$ George P. Fletcher, Fairness and Utility in Tort Theory, 85 Harv. L. Rev. 537, 537 (1972).

${ }^{10} I d$. en 550.
} 
de la responsabilidad por daños basada en la justicia correctiva. ${ }^{11} \mathrm{Con}$ el objetivo de explicar el régimen de responsabilidad extracontractual realmente existente en el common law, estos filósofos defienden una teoría que está inspirada ampliamente en Aristóteles y en Kant y que busca tener un poder explicativo mayor que el que posee el análisis economico de la responsabilidad extracontractual. Más específicamente, tales autores sostienen que el análisis económico deja de lado los aspectos morales centrales de la responsabilidad extracontractual, tales como el patrón de interacción en el que el daño tuvo lugar o el tipo de control que el demandado tuvo sobre sobre el resultado dañoso. Por ejemplo, Wright sostiene que el common law le da menos importancia a la utilidad del demandado que a la del demandante, lo que parece contradecir los supuestos del análisis económico. Según la visión basada en la justicia correctiva, la mejor manera de explicar la responsabilidad extracontractual es asumiendo que aplica un principio moral no consecuencialista. En la formulación de Coleman, dicho principio sostiene que (i) una persona es responsable por cualquier pérdida que inflige injustamente a otra, y (ii) si una persona es responsable de la pérdida que otra sufre, debe compensarla por completo. Coleman sostiene que la justicia correctiva establece principios abstractos de equidad que gobiernan la asignación de los infortunios que presenta la vida.

El segundo ejemplo es la explicación filosófica del derecho de los contratos. Según el Profesor Charles Fried, un contrato es un intercambio de promesas y, por ende, el incumplimiento contractual es análogo al incumplimiento de una promesa. ${ }^{12}$ Fried funda la obligación moral de cumplir con las promesas en el hecho de que incumplir una promesa viola la autonomía del tenedor de la promesa pues conlleva un abuso de la confianza que uno creó al prometer. Otros teóricos del derecho, tales como Randy Barnett, Peter Benson y Alan Brudner ven a la obligación que surge de un contrato como una obligación basada en la propiedad, antes que como una promisoria. ${ }^{13}$

${ }^{11}$ Ver Jules L. Coleman, Risks and Wrongs (1992); Jules L. Coleman, The Practice of Principle: In Defence of a Pragmatist Approach to Legal Theory (2001); Ernest J. Weinrib, The Idea of Private Law (1995); Stephen R. Perry, Responsibility for Outcomes, Risk, and the Law of Torts, en Philosophy and the LaW of TorTs 72 (Gerald J. Postema ed., 2001); Richard W. Wright, Right, Justice and Tort Law, en Philosophical Foundations of Tort Law 159 (David G. Owen ed., 1995); Richard W. Wright, The Standards of Care in Negligence Law, en PhiloSOPHICAL Foundations of TORT LAW, supra at 249.

12 Ver Charles Fried, Contract As Promise: A Theory of Contractual Obligation (1981).

${ }^{13}$ Ver Alan Brudner, The Unity of the Common Law: Studies in Hegelian Jurisprudence cap. 3 (1995); Randy E. Barnett, A Consent Theory of Contract, 86 Colum. L. Rev. 269 (1986); Peter Benson, The Unity of Contract Law, en The Theory of Contract Law: New Essays 118 (Peter Benson ed., 2001). 
Al hacer un contrato, según ellos, uno consiente a la transferencia de su propiedad, definida o bien como una cosa material o como un valor económico. Según esta visión, el derecho de los contratos respeta los derechos de propiedad que surgen de un contrato. Ni el enfoque basado en las promesas ni el basado en la propiedad apelan a la maximización del bienestar para explicar la obligación contractual.

\section{II. ¿Se pueden aplicar los dos paradigmas al derecho romanista?}

Tal como dije al comienzo de este ensayo, me interesa analizar si los dos paradigmas son aplicables al derecho romanista o codificado. Si los juristas civilistas introdujeran estos paradigmas en sus investigaciones, la naturaleza de la ciencia jurídica podría cambiar nuevamente, tal como cambió después del surgimiento de la escuela del derecho natural. Incluso así, no podemos esperar un alineamiento automático de la doctrina civilista con la investigación que se desarrolla en el marco del common law, especialmente en el derecho privado. Debido a las diferentes evoluciones históricas del common law y del derecho romanista, el valor explicativo relativo del paradigma económico y del filósofico es diferente para cada sistema legal. Me contento con ilustrar, a través de dos ejemplos, cómo las instituciones civilistas y del common law pueden ser explicadas en función de paradigmas teóricos diferentes.

Comenzaré con el paradigma filosófico, en el que la respuesta es más simple. En términos históricos, el paradigma filosófico surgió como un modo para entender el derecho romanista. Recordemos que el enfoque filosófico del derecho se nutre de las teorías iusnaturalistas racionalistas que surgieron durante los siglos XVII y XVIII. Más aún, Grocio, Pufendorf y Kant construyeron sus sistemas de derecho natural a fin de sistematizar los principios fundamentales del Corpus Iuris Civilis. Como es bien sabido, el Derecho Romano fue objeto de estudio en la Europa Continental desde el fin del siglo XI. Por el contrario, el Profesor Coing sostiene que el common law inglés se desarrolló independientemente del Derecho Romano Canónico. ${ }^{14}$ La filosofía del derecho natural racionalista no sólo dio fundamentos abstractos a las instituciones principales del Derecho Romano, tales como la posesión, la propiedad, y el contrato, sino que también introdujo el ideal de la codificación y, al hacerlo, transformó al Derecho Romano en un sistema formal basado en la razón. Respecto de la la influencia del derecho natural racionalista en la ciencia jurídica europea, Franz Wieacker observa que:

${ }^{14}$ Ver Helmut Coing, The Roman Law as Ius Commune on the Continent, 89 L. Q. Rev. 505 (1973). Según entiendo, esto es consistente con la influencia intelectual tradicional del Derecho Romano sobre los jueces ingleses. 
"Despues de Hobbes y de Pufendorf...la prueba lógica en un sistema coherente se convirtio en la verdadera piedra de toque de la Ley de la Razón de la consistencia de sus axiomas metodológicos. En el siglo XVIII comenzó a ordenar las explicaciones del derecho positivo, y de ese modo creó el sistema que todavía domina los códigos y los libros de texto jurídicos del continente europeo". ${ }^{15}$

No es posible entender la ciencia jurídica alemana, por ejemplo, sin considerar la influencia de los abogados iusnaturalistas racionalistas tales como Pufendorf y Kant. De hecho, la parte más abstracta del trabajo teórico de Savigny puede verse como una teoría filosófica del derecho civil. Si bien todo este proceso intelectual fascinante fue oscurecido por la codificación, no hay duda de que el paradigma filosófico puede aplicarse al derecho romanista. De hecho, el paradigma filosófico está inspirado en la escuela racionalista del derecho natural, históricamente asociada con el derecho romanista. Paradójicamente, el cuerpo de literatura que los filósofos del derecho norteamericanos están produciendo en la actualidad provee una explicación del common law, un sistema que históricamente no tiene conexión con tal tradición intelectual. Uno debería esperar una aplicación más directa del paradigma filosófico a la comprensión del derecho romanista. Sostendré que, por cierto, tal es el caso.

Las acciones por incumplimiento contractual son mi primer ejemplo. Siguiendo al derecho romano clásico, el common law estableció la indemnización por daños y perjuicios como la acción principal por incumplimiento contractual. Los tribunales pueden ordenar la ejecución forzosa sólo en circunstancias especiales; por ejemplo, con la regla del daño irreparable, decretan el cumplimiento de la obligación sólo en las circunstancias especiales en las que la indemnización por daños es inadecuada. ${ }^{16}$ Por el contrario, en el derecho romanista la acción principal por incumplimiento contractual es la ejecución de la obligación, antes que la indemnización. Por ejemplo, el artículo 1134 del Codigo Civil francés establece que los contratos deben ejecutarse de buena fe, y el artículo 1136 establece que una obligación de dar implica una obligación de entregar la cosa y de preservarla hasta la entrega. ${ }^{17}$ Del mismo modo, el Codigo Civil argentino establece en el artículo 505 que el acreedor, en caso de incumplimiento de un contrato, tiene el derecho de elegir entre las siguientes medidas: obligar al cumplimiento de

${ }^{15}$ Franz Wieacker, A History of Private Law in Europe 218 (Tony Weir trans., 1995).

${ }^{16}$ Sin embargo, el Profesor Laycock mostró que los tribunales usualmente entienden que las indemnizaciones compensatorias son inadecuadas y, entonces, ordenan el cumplimiento específico. Ver Douglas Laycock, The Death of the Irreparable Injury Rule (1991). Agradezco a Tom Ulen por llamar mi atención respecto de los descubrimientos de Laycock.

${ }^{17}$ Code Civil [C. civ.] art. 1134, 1136 (Fr.). 
la obligación, hacer que un tercero ejecute el contrato a expensas del deudor, $\mathrm{u}$ obtener las indemnizaciones pertinentes. ${ }^{18}$

Los autores de un libro bien conocido de derecho comparado escriben: "El principio de que las obligaciones, especialmente las obligaciones contractuales, pueden como regla hacerse cumplir compulsivamente y que en general es el acreedor y no el tribunal el que elige entre el cumplimiento específico y una accion no específica, ha sido adoptado en la gran mayoría de los sistemas de derecho romanista." ${ }^{19}$ Sin embargo, esto sólo es cierto respecto de las obligaciones de dar. Los sistemas de derecho civil adoptan modalidades diferentes respecto de las obligaciones de hacer. La posición suave es adoptada por el Código Civil francés, que en el artículo 1142 establece que una obligación de hacer se convierte en una obligación de indemnizar en caso de incumplimiento. ${ }^{20} \mathrm{El}$ Código Civil argentino sigue la interpretación de Marcadé del Código Civil francés. Así, el artículo 629 establece que el acreedor puede exigir el cumplimiento forzado de una obligación de hacer, excepto cuando hacerlo requiera ejercer violencia sobre el deudor. ${ }^{21}$ El Código Civil alemán (BGB) adopta la posición dura. En su artículo 41, establece que "[e]1 efecto de una obligacion es que el acreedor tiene derecho a reclamar el cumplimiento específico de parte del deudor."22 Todavía más, el Código Civil Procesal alemán faculta a los tribunales a aplicar multas y pena de prisión para asegurar el cumplimiento de una obligación de hacer cuando el acto jurídico en cuestión no puede ser ejecutado por un tercero. ${ }^{23}$

Las diferencias ya mencionadas indican que el derecho contractual civilista y el derecho contractual anglosajón están sujetos a diferentes tipos de explicaciones. De hecho, el derecho contractual civilista tuvo influencias de la escuela del derecho natural y de su énfasis en la autonomía individual, mientras que las acciones por incumplimiento contractual en el common law imitan la practicidad del Derecho Romano. Bajo la influencia de los juristas iusnaturalistas, el derecho de los contratos en el derecho civil fue concebido en torno de la idea de autonomia individual, lo que lo hace recalcitrante a los enfoques basados en la maximización del bienestar. Tal como explica la Profesora Catherine Valcke, "[1] os tres principios fundacionales del derecho contractual civilista -libertad contractual, fuerza vinculante de los contratos,

${ }^{18}$ Código Civil [Cód. Civ.] art. 505 (Arg.).

${ }^{19}$ Rudolf B. Schlesinger et al., Comparative Law 665 (5th ed. 1988).

${ }^{20}$ C. CIV. art. 1142.

${ }^{21}$ Cód. Civ. art. 629.

${ }^{22} \S 241$ BGB (Ger.) (traducido en The German Civil Code (Simon L. Goren trans., Rev. ed. 1994)).

${ }^{23} \S 888$ ZPO (Zivilprozessordnung). 
y el consensualismo- derivan directamente de los postulados de la voluntad autónoma de Kant."24

Hay dos argumentos que apoyan mi sugerencia. Primero, dije que la indemnización en función de la expectativa es eficiente como acción por incumplimiento contractual. Por el contrario, el cumplimiento específico sólo puede ser defendido como una acción eficiente en circunstancias especiales (e.g., cuando los costos de renegociación son altos). ${ }^{25}$ Puesto que la indemnización en función de la expectativa es la acción principal en el common law, el paradigma económico ofrece una explicación exitosa de este aspecto del common law. Segundo, la teoría de la obligación contractual como una obligación promisoria puede explicar adecuadamente por qué el cumplimiento específico es la acción principal en el derecho romanista. De hecho, la provisión general del cumplimiento específico es un corolario natural de la idea de que los contratos son válidos como un ejercicio de la autonomía individual. Esta idea ejerció una influencia decisiva en el desarrollo del derecho contractual civilista. Si la fuerza vinculante de los contratos depende de un acto de la voluntad, la indemnización monetaria a lo sumo podría ser la segunda mejor opción.

Es interesante que los analistas económicos del derecho llegan a una conclusión similar. Así, los Profesores Kaplow y Shavell sostuvieron que la explicación del derecho contractual basada en la obligacion de cumplir con las promesas deforma el common law porque implica la adopción del cumplimiento específico como la acción principal por incumplimiento contractual. ${ }^{26}$ Pues bien, cuando se trata del derecho romanista, el resultado se revierte. Es en verdad la explicación económica la que deforma al derecho civil porque el derecho civil no permite incumplir un contrato y pagar indemnización, con la excepción de los casos en que el acreedor opta por la indemnización o, en el sistema francés, cuando el contrato da lugar a una obligación de hacer. La idea de que hay un incumplimiento eficiente (en particular, de una obligación de dar) es completamente ajena al derecho contractual civilista. No es la economía, sino más bien la filosofía moral la que tiene el gancho inicial para explicar este aspecto del derecho civil. Esto apoya mi argumento de que la filosofía moral está en una posicion mejor que el paradigma económico para explicar el derecho contractual civilista.

${ }^{24}$ Catherine Valcke, The Unhappy Marriage of Corrective and Distributive Justice in the New Civil Code of Quebec, 46 U. Toronto L. J. 539, 567 (1996).

${ }^{25}$ Sin embargo, el Profesor Ulen sostiene que el cumplimiento específico es más eficiente que los daños de expectativa porque evita la necesidad de estimar valores subjetivos. Ver Thomas S. Ulen, The Efficiency of Specific Performance: Toward a Unified Theory of Contract Remedies, 83 Мich. L. Rev. 341 (1984).

${ }^{26}$ Ver Kaplow \& Shavell, supra nota 1. 
Al mismo tiempo, este último paradigma parece funcionar bien en el common law.

En segundo lugar, una explicación posible del cambio desde la indemnización monetaria al cumplimiento específico ve a tal cambio como conectado a la idea que los filósofos isunaturalistas adoptaron con respecto a la transferencia de la propiedad y del riesgo en la venta. En el derecho romano, como regla, el riesgo del daño o de la destrucción de la cosa pasaba al comprador al tiempo del acuerdo, pero la propiedad sólo pasaba al comprador con la tradición. Tal como indica el Profesor Alan Watson, Grocio, Pufendorf y Barbeyrac creían que era irracional ubicar en diferentes tiempos la transferencia de la propiedad y la del riesgo. Mientras que Grocio y Barbeyrac defendían la posición de que tanto la propiedad como el riesgo debían pasar al comprador al tiempo del acuerdo, Pufendorf afirmaba que la transferencia debía ocurrir al momento de la entrega de la cosa. Bajo la influencia de Barbeyrac, el Código Civil francés cambió la regla romana y estableció que tanto la propiedad como el riesgo se transferían al comprador al momento del acuerdo. ${ }^{27}$ Por el contrario, el Código Civil argentino y el BGB siguieron la posición de Pufendorf y establecieron que el riesgo y la propiedad pasan conjuntamente al comprador, pero al tiempo de la tradición.

Enfrentado con estas diferencias enigmáticas, el análisis económico del derecho no parece ser de ayuda. Desde un punto de vista económico, es eficiente hacer que un costo evitable recaiga sobre la parte que puede reducir el riesgo de que tal pérdida ocurra al costo menor y que, por tal razón, puede asegurarse contra ella. Pero, por hipótesis, el tipo de control en cuestión está fuera del alcance del deudor. Entonces, uno podría sugerir que las diferencias son casi accidentales. Defendiendo esta posición, Watson escribe: "el rechazo francés a las reglas romanas en este punto no fue resultado del desarrollo social, ni tampoco se debió a las debilidades prácticas del sistema más viejo, ni fue consecuencia de una toma de conciencia de la necesidad lógica de la posición que ellos preferían." ${ }^{28}$ Sin embargo, Watson no logra ofrecer una explicación teórica de las reglas accidentales. Uno podría sugerir que muchas normas jurídicas carecen de una razón de ser específica. Tal como las normas lingüísticas, son mecanismos útiles para coordinar las acciones individuales. ${ }^{29}$ Según esta posición, es irrelevante en qué momento tiene lugar la transferencia del riesgo y de la propiedad; sólo importa que todos estemos de acuerdo en una única regla. Quizás Savigny tenía en mente

27 Ver Alan Watson, Legal Transplants: An Approach to Comparative Law cap. 14 (1993).

${ }^{28} \mathrm{Id}$. at 85 .

${ }^{29}$ Ver Russell Hardin, Liberalism, Constitutionalism, and Democracy cap.3 (1999). 
la idea de coordinación cuando esbozó su analogía famosa entre el derecho y el lenguaje. ${ }^{30}$

Uno también podría intentar una explicación filosófica. Esta explicación podría ser simple y plausible en el derecho civil francés. Recordemos que, en el Código francés, la propiedad pasa al comprador al momento del consentimiento. Esta regla encaja bien con el establecimiento del cumplimiento especifíco como la acción principal por incumplimiento de las obligaciones de dar. Si el título de propiedad pasa al comprador cuando se hace el acuerdo, el comprador obviamente tendría que tener la opción de requerir la entrega de su propiedad. Mi punto no es que los redactores franceses del proyecto de código cambiaron el sistema de transferencia romano ubicándolo al momento del acuerdo porque el derecho francés ya había sustituido el cumplimiento específico por la indemnización monetaria como acción principal por incumplimiento contractual. Tampoco quiero decir que la teoría proprietarista es la mejor explicación filosófica de la preferencia del derecho civil por el cumplimiento específico. En vez, sostendré que ambos cambios pueden explicarse a la luz de la concepción del derecho de los contratos basada en la idea de autonomía a la que adhiere la escuela del derecho natural. En aquellos aspectos en los que la filosofía moral influyó en el derecho civil, el análisis económico del derecho no es de ayuda, y el filósofo triunfa.

Mi segunda ilustración es la responsabilidad civil. La mayoría de los códigos civiles establecen la responsabilidad subjetiva como el paradigma fundamental de la responsabilidad civil. En el derecho civil, la responsabilidad requiere de causalidad y de culpa. De este modo, el artículo 1382 del Código francés dice: "Cualquier acto de un hombre que cause daño a otro obliga a aquel por cuya culpa se causó el daño a repararlo". ${ }^{31}$ El mismo texto fue reproducido en el artículo 2315, párrafo A, del Código Civil de Luisiana, ${ }^{32}$ e inspiró el artículo 1109 del Código Civil argentino. ${ }^{33}$ Puesto que la teoría de responsabilidad civil tradicional en el derecho civil requiere culpa, es afín a la idea de justicia correctiva.

Tal como mostró el Profesor Francesco Parisi, la posición central del principio de la culpa en el derecho civil es el resultado de un proceso histórico largo que comenzó con la ética aristotélica y su influencia en los tres principios fundamentales del derecho romano: honeste vivere, suum cuique tribuere y alterum non laedere. En particular, el último cánon estableció las

\footnotetext{
${ }^{30} \mathrm{Ver}$ Frederick Charles von Savigny, Of the Vocation of Our Age for Legislation and JURISPRUDENCE (Abraham Hayward trans., photo. reprint 1977).

${ }^{31}$ C. Civ. art. 1382 (traducido en The French Civil Code (John H. Crabb trans., rev. ed., 1995)).

32 La. Rev. Stat. Ann. § 2315(A) (1997 \& 2004 Supp.).

${ }^{33}$ Cód. Civ. art. 1109.
} 
bases filosóficas para elaborar casuísticamente el sistema de responsabilidad civil en el período clásico. La Lex Aquilia introdujo el requisito de iniuria, pero no tenía un principio general de responsabilidad civil. Tomás de Aquino y el jurista humanista Hugo Donellus contribuyeron al surgimiento gradual de un sistema de responsabilidad civil basado en la culpa en Europa Continental. Finalmente, las ideas iusnaturalistas racionalistas de Hugo Grocio tuvieron un gran impacto intelectual en Jean Domat y Robert Pothier, cuyos trabajos fueron las fuentes principales para la redacción del proyecto del Código Civil francés. ${ }^{34}$

El establecimiento del principio de la culpa en el derecho civil europeo es el resultado de siglos de interacción entre ideas éticas y jurídicas. El supuesto básico es que nadie puede ser declarado responsable por resultados que no son atribuibles a sus elecciones voluntarias. La idea de justicia correctiva requiere neutralizar el impacto del azar o de la mala suerte en la responsabilidad jurídica. Como corolario de la idea de justicia correctiva, el principio de la culpa está profundamente enraigado en el derecho civil . Debido a las conexiones históricas entre el derecho natural y el derecho civil, las explicaciones filosóficas de la responsabilidad extracontractual son más adecuadas para explicar el sistema civilista.

Con el nacimiento de las innovaciones técnicas y de la producción industrial, y los riesgos acompañantes para las personas y la propiedad, la noción de culpa se desvaneció en el sistema de responsabilidad civilista. De hecho, para mejorar la posición de los vecinos, los peatones, los consumidores y los trabajadores de las fábricas, el derecho civil comenzó a relajar la teoría monolítica de responsabilidad civil aceptando soluciones que no incluían a la culpa. En estos términos, los juristas y los tribunales franceses propusieron la teoría del riesgo para atenuar el principio de la culpa establecido en el articulo 1382 del Código Civil mediante la interpretación extensiva del artículo 1384, primer párrafo, que establece la responsabilidad civil por el hecho de las cosas que una persona tiene bajo su custodia. ${ }^{35}$

No está fuera de duda cómo entender la relajación del principio de la culpa en el derecho civil. Por un lado, el paradigma económico puede ofrecer una explicación elegante de la responsabilidad objetiva sobre la base del principio económico de prevención óptima. Por el otro lado, el paradigma filosófico podría intentar explicar el cambio hacia la responsabilidad objetiva en términos de la justicia correctiva. Tal como dije antes, George Fletcher

\footnotetext{
${ }^{34}$ Ver James Gordley, Tort Law in the Aristotelian Tradition, en Philosophical Foundations of Tort Law, supra nota 11, en 131; Francesco Parisi, Alterum Non Laedere: An Intellectual History of Civil Liability, 39 Am. J. JuRIs. 317 (1994).

${ }^{35}$ C. civ. art. 1384. Ver 1 Henri Mazeaud \& León Mazeaud, Traité Théorique et Pratique de la Responsabilité civile Délictuelle et Contractuelle 81-88 (4th ed. 1947).
} 
propuso una explicación de la responsabilidad objetiva que ve a dicho tipo de responsabilidad como una implementación del derecho de la víctima a ser compensada por daños no-recíprocos. ${ }^{36}$ La propuesta de Fletcher sugiere que es una pregunta abierta si la responsabilidad objetiva requiere una explicación económica y no filosófica. Lo que es seguro, sin embargo, es que la concepción clásica de la responsabilidad civil puede ser explicada fácilmente en términos de la justicia correctiva.

Las explicaciones filosóficas de la responsabilidad extracontractual basadas en la idea de culpa se multiplicaron en los ultimos años. Paradójicamente, tales explicaciones son invocadas para explicar el common law, en el que el principio de la culpa nunca adquirió la posición dominante que tradicionalmente tenía en el derecho civil. De hecho, en los casos antiguos del common law, tales como Weaver v. Ward ${ }^{37}$ y Dickenson v. Watson, ${ }^{38}$ se entendía que la responsabilidad civil surgía de la violación de la propiedad, y no se requería culpa. La interferencia con los derechos a la integridad corporal o las cosas externas era lo que constituía la conducta indebida. La culpa sólo apareció como requisito de la responsabilidad civil al fin de la Edad Media, con la aparición del mandamiento de violación de la propiedad. Según la visión histórica ortodoxa, sólo hacia mediados del siglo XIX surgió en el derecho norteamericano un sistema comprensivo de responsabilidad basada en la culpa como un medio para subsidiar a las nuevas empresas industriales. ${ }^{39}$ Harvey v. Dunlop, ${ }^{40}$ en 1843, y Brown v. Kendall, ${ }^{41}$ en 1850, introdujeron el requisito general de existencia de culpa en la responsabilidad civil. Al decidir el primer caso, el Presidente del Tribunal de Nueva York sostuvo: "No se puede encontrar ningún caso o principio, o si se lo encuentra no se puede mantener, que sujete a un individuo a responsabilidad por un acto ejecutado sin que medie culpa de su parte". ${ }^{42}$ Increíblemente, los tribunales norteamericanos "descubrieron" este principio al menos dos siglos más tarde que el derecho europeo. Incluso despues de Harvey v. Dunlop, no estaba fuera de toda duda la prevalencia del principio de la culpa. Por ejemplo, en Hay v. Cohoes, ${ }^{43}$ un caso de explosión decidido en 1849, el mismo

\footnotetext{
${ }^{36}$ Ver Fletcher, supra nota 9.

3780 Eng. Rep. 284 (1616).

3884 Eng. Rep. 1218 (1682).

$39 \mathrm{Ver}$ Lawrence M. Friedman, A History of American Law 409-10 (1973); Morton J. Horwitz, The Transformation of American Law, 1780-1860, en 85-99 (1977).

${ }^{40} 1843$ Hill \& Den. 193, 194-95 (N.Y. Sup. Ct.).

${ }^{41} 60$ Mass. 292, 296 (1850).

${ }^{42}$ Harvey, 1843 Hill \& Den. at 194. Ver también Charles O. Gregory, Trespass to Negligence to Absolute Liability, 37 VA. L. REV. 359, 368 (1951).

432 N.Y. 159, 161 (1849).
} 
tribunal de Nueva York aplicó el viejo principio sic utere tuo, una doctrina de invasión de la tierra que sólo requería invasión de la tierra y causación del daño para que hubiera responsabilidad civil. Más aún, en el derecho inglés del siglo XIX la culpa no se había convertido en un principio fundamental, tal como lo muestra la decisión del tribunal de Exchequer en Fletcher $v$. Rylands,${ }^{44}$ un caso de un derrame de agua de 1865 . Con mayor claridad, Lord Branwell estableció que la acción por daños podía mantenerse "sobre la base de que los demandados habían hecho que el agua fluyera hacia las minas del demandante y que, si no fuera por el acto de los demandados, el agua no hubiera ido hacia alli". ${ }^{45}$ Lord Branwell agregó que "la inocencia de los demandados, cualquiera pueda ser su relevancia moral en el caso, es irrelevante frente al derecho". ${ }^{46}$

Podría cuestionarse si la responsabilidad objetiva era el régimen tradicional en el common law antes del surgimiento del principio de la culpa. El Profesor Robert Rabin sostiene, por ejemplo, que la responsabilidad basada en el principio de la culpa prevaleció "contra un trasfondo de ausencia de responsabilidad, no de responsabilidad objetiva". ${ }^{47}$ La idea de Rabin es que los daños industriales no tenían precedentes en el common law y que los tribunales norteamericanos tendieron a resolverlos apelando a la idea de culpa desde el principio. De este modo, cita Losee v. Clute ${ }^{48}$ y Losee v. Bucha$n a n,{ }^{49}$ dos casos de calderas de vapor decididos en 1873 , en los que el tribunal rechazó la doctrina de responsabilidad objetiva de Rylands y estableció que debía probarse culpa para que el demandado sea declarado responsable por daño intencional. En la misma línea, el Profesor Gary Schwartz refuta la interpretación del supuesto cambio desde la responsabilidad objetiva hacia la responsabilidad subjetiva que visualiza tal cambio como un subsidio a las empresas. Para ello analiza la responsabilidad extracontractual del siglo XIX tal como se desarrolló en California y en New Hampshire. ${ }^{50}$ Schwartz muestra de un modo convincente que la compensación por daños personales se decidió habitualmente sobre la base del principio de culpa durante la primera mitad del siglo XIX, y que la responsabilidad objetiva estaba confinada fundamentalmente a los casos de perjuicios. En campos tales como el

44159 Eng. Rep. 737 (1865).

${ }^{45}$ Id. en 744 .

${ }^{46} I d$.

${ }^{47}$ Robert L. Rabin, The Historical Development of the Fault Principle: A Reinterpretation, 15 Ga. L. REv. 925, 938 (1981).

4851 N.Y. 494 (1873).

4951 N.Y. 476 (1873).

${ }^{50}$ Gary T. Schwartz, Tort Law and the Economy in Nineteenth-Century America: A Reinterpretation, 90 YALE L.J. 1717 (1981). 
del transporte y de las fábricas textiles, los tribunales de California y New Hampshire tendían a favorecer la posición de los demandantes mediante la doctrina res ipsa loquitur y la negación de la culpa concurrente y rechazaban argumentos favorables al desarrollo económico para justificar la asunción de riesgos industriales.

Dejando de lado las controversias acerca del trasfondo contra el que el principio de la culpa adquirió un rol decisivo en el derecho norteamericano del siglo XIX, hay pocas dudas de que el paradigma tradicional de responsabilidad en el common law pone énfasis en la invasión de los derechos de propiedad y del daño directo o indirecto que resulta de dicha invasión, mientras que el paradigma básico en el derecho civil está basado en una idea moralizada de culpa. A pesar del contraste histórico entre el common law y el derecho civil, los filósofos del derecho en las jurisdicciones de derecho civil usualmente ignoran el tipo de análisis filosóficos que sus colegas del common law cultivaron recientemente. Puesto que el paradigma filosófico es en gran parte una reacción contra el análisis económico del derecho, la falta de interés puede deberse a la recepción difícil y lenta del análisis económico del derecho en los países de derecho civil. ${ }^{51} \mathrm{Mi}$ sugerencia es que podemos explicar este fenómeno teniendo en cuenta un aspecto fundamental del derecho civil. En el derecho civil, las sentencias están basadas en razones formales, esto es, en normas definidas por sus atributos formales, antes que en consideraciones morales, económicas, políticas, institucionales o consideraciones sociales de otro tipo. Mientras que del juez norteamericano, por ejemplo, habitualmente se espera que use un razonamiento basado en políticas para interpretar los precedentes y para establecer nuevas normas, el juez civilista está obligado a aplicar el código civil o el sistema formal de ciencia jurídica que se mezcla con el código. La ciencia jurídica es más formal que la investigación del common law. El razonamiento en el derecho civil comienza típicamente con premisas y conceptos abstractos y, entonces, deja poco lugar para el tipo de razonamiento consecuencialista, que mira hacia el futuro en el que se basa el análisis económico del derecho. Las consideraciones económicas no están completamente ausentes en la ciencia jurídica, pero su rol es restringido. Cuando el razonamiento formal no lleva a una respuesta definitiva a una cuestión jurídica, el científico jurídico usualmente recurre a la ficción del legislador racional. ${ }^{52}$ Esto significa que,

${ }^{51} \mathrm{Ver}$ R. Cooter and J. Gordley, Economic Analysis in Civil Law Countries: Past, Present, Future, 11 Int'L. Rev. L. \& ECon. 261 (1991). Ver también los otros artículos publicados en esta edición.

${ }^{52}$ Ver Carlos Santiago Nino, Consideraciones Sobre la Dogmática Jurídica (1974); Leszek Nowak, A Concept of Rational Legislator, en Polish Contributions to the Theory and Philosophy of LAW 137 (Zygmunt Ziembiński ed., 1987). 
en la ciencia jurídica, el razonamiento consecuencialista y económico se limita a los casos difíciles.

El derecho inglés también tiene un sistema de fuentes jurídicas formales, pues los precedentes son razones formales. Los Profesores Patrick Atiyah y Robert Summers mostraron minuciosamente que las doctrinas de las fuentes del derecho norteamericanas e inglesas son muy distintas en términos de las formalidad. ${ }^{53}$ En efecto, el stare decisis es una doctrina más rígida en el derecho inglés, que deja poco lugar para el análisis de políticas explícito. Es el common law norteamericano, antes que el derecho inglés, el que puede contrastarse con el derecho civil en lo que respecta a la formalidad. En la misma línea, el Profesor Richard Posner sostuvo recientemente que el common law inglés y el derecho civil europeo son comparables en términos de la formalidad. Tanto los jueces ingleses como los europeos se entrenan en las carreras burocráticas que aceptan como axiomática la separación de funciones entre la legislatura y el poder judicial. Sólo en Estados Unidos los jueces se sienten libres para emplear sistemáticamente el razonamiento consecuencialista e instrumental. ${ }^{54}$ Esto podría explicar por qué el análisis económico del derecho es aceptado más fácilmente en los círculos jurídicos norteamericanos que en los ingleses y europeos.

Intenté explicar por qué el análisis económico del derecho no tiene un camino fácil para entrar al derecho civil. Esto no quiere decir que el análisis económico del derecho sea irrelevante para explicar el derecho civil. Ya indiqué que la tendencia hacia la responsabilidad que no está basada en la culpa puede explicarse en función de la prevención óptima. Todavía más, los análisis de política se manifiestan en los tiempos de codificación o de enmiendas al código. Daré dos ejemplos para mostrar la importancia del análisis económico para la legislación civilista. Mi primer ejemplo es la redacción del BGB. El profesor Jürgen Backhaus sostiene que "[e]1 Código Civil [alemán], en su última versión, se aprobó con la colaboración explícita de los economistas más importantes de su tiempos en Alemania, y estaba basado en razonamiento económico explícito". ${ }^{55}$ Él explica que un grupo de economistas, en particular Otto von Gierke, publicó artículos en el Jahrbuch fur Gesetzgebung, Verwaltung und Volkswirtschaft im Deutschen Reich criticando los primeros proyectos de 1887 y 1889 . La crítica de los economistas llevó a la creación de un segundo comité en 1890, que desarro-

${ }^{53}$ Ver P. S. Atiyah \& Robert S. Summers, Form and Substance in Anglo-American Law (1987).

${ }^{54} \mathrm{Ver}$ Richard A. Posner, Law and Legal Theory in England and America (1996).

55 Jürgen G. Backhaus, Otto von Gierke (1841-1921), en The Elgar Companion to Law AND ECONOMICs 313, 314 (Jürgen G. Backhaus ed., 1999). 
lló un proyecto completamente revisado en 1895. Si bien Backhaus sostiene que el nuevo proyecto, finalmente aprobado en 1896, concordaba mejor con las necesidades de una economía de mercado industrial, no especifica las revisiones que supuestamente produjeron tal resultado.

Mi segundo ejemplo da más información fáctica. Como es bien sabido, todos los códigos civiles regulan los derechos reales. Es interesante que el redactor del Código Civil argentino, Dalmacio Vélez Sársfield, introdujo en el código diversas normas que limitan la capacidad de los individuos para dividir en muchas partes los paquetes de derechos de propiedad. En particular, el artículo 2502 prohíbe la creación de nuevos tipos de derechos reales (numerus clausus). ${ }^{56}$ En la nota a tal artículo, Vélez Sársfield menciona los obstáculos a la explotación económica presentados por la descomposición de la propiedad en la Europa medieval, en particular en España. ${ }^{57}$ Vélez Sársfield justifica tal disposición diciendo: "La multiplicidad de derechos reales sobre unos mismos bienes es una fuente fecunda de complicaciones y de pleitos y puede perjudicar mucho a la explotación de esos bienes y la libre circulación de las propiedades...". ${ }^{58}$ Todavía más, en la nota al artículo 2503, justifica la supresión de la enfiteusis y del derecho del superficiario, que expresamente prohíbe en el artículo 2614, junto con todo tipo de prohibiciones a la venta. ${ }^{59}$ Las normas del Código Civil argentino que garantizan la unidad de la propiedad evitando su desintegración voluntaria tienen un fundamento económico claro, sistematizado recientemente por el Profesor Michael Heller ${ }^{60}$ Heller estudia cómo las actividades económicas se ven afectadas por la descomposición de los derechos de propiedad en las manos de diversos titulares. Al establecer la propiedad privada unida y completa, Vélez Sársfield intentó evitar las ineficiencias asociadas con la -así llamada- "tragedia de los anti-comunes", que ocurre cuando los costos de transacción, la conducta estratégica o las deficiencias cognitivas evitan que los titulares de diversos derechos de propiedad se junten en un paquete único de derechos. Sin duda, Vélez Sársfield no conocía esta noción moderna, pero tenía una comprensión intuitiva refinada de la fundamentación de la propiedad no fragmentada. Tal como sabemos actualmente, la tragedia de los anti-comunes amenaza el uso y la enajenación efectiva de la propiedad.

\footnotetext{
${ }^{56}$ CóD. Civ. art. 2502.

${ }^{57} \mathrm{Id}$.

${ }^{58} \mathrm{Id}$.

${ }^{59}$ CóD. CIV. art. 2503, 2614.

${ }^{60}$ See Michael A. Heller, The Tragedy of the Anticommons: Property in the Transition from Marx to Markets, 111 HARv. L. Rev. 621 (1998).
} 
El rol del análisis de políticas en los tiempos de cambios jurídicos sugiere que el código civil también tiene fundamentos económicos. Dar a conocer tales decisiones de políticas puede ser un modo de explicar las nociones abstractas y formales. Esta posibilidad no puede descartarse de antemano. De hecho, la literatura económica en aumento sobre el derecho civil sugiere que los juristas civilistas tienen mucho para aprender del análisis económico. ${ }^{61}$

\section{Conclusión}

Tanto el paradigma filosófico como el económico pueden ser de ayuda para entender el derecho, ya sea el common law o el derecho civil. Sin embargo, sostuve que la importancia relativa de tales paradigmas es diferente en el common law y en el derecho civil. La justicia y la autonomía son valores más importantes en el derecho civil, dados los fundamentos filosóficos de los códigos civiles y de la ciencia jurídica civilista. De todos modos, el análisis económico del derecho puede ser de ayuda para entender los campos del derecho civil que se están alejando de su estructura individualista clásica para dirigirse hacia modos colectivistas de maximización del bienestar.

(Trad. de Martín Hevia)

${ }^{61} \mathrm{Ver}$, e.g., 2 Civil LaW ANd Economics, Encyclopedia of LaW AND Economics (Boudewijn Bouckaert \& Gerrit De Geest eds., 2000). Para un análisis económico del fenómeno de la codificación en sí mismo, ver Jean-Michel Josselin \& Alain Marciano, The Making of the French Civil Code: An Economic Interpretation, 14 Eur. J.L. \& Econ. 193 (2002). 